\title{
Surgical management of orchitis in Gir bullock by scrotal ablation technique
}

\author{
V. Mahesh, H. Rashmitha*, Preetham Kumar S.V., Shivaraju E. and B.N. \\ Nagaraja
}

Department of Veterinary Surgery and Radiology, Veterinary College, Hebbal, Bengaluru, Karanataka Veterinary, Animal and Fisheries Sciences University, Bidar.

*Corresponding author: e- mail - rashmithaheerekar@gmail.com

Journal of Livestock Science (ISSN online 2277-6214) 13: 38-40

Received on 17/9/21; Accepted on 22/12/21; Published on 10/1/22

doi. 10.33259/JLivestSci.2022.38-40

\begin{abstract}
A Gir bullock of four years of age was presented to the Department of Veterinary Surgery and Radiology, Hebbal, Bengaluru with the complaint of swelling in the scrotal region since one month. It had a history of faulty castration. Upon aspiration of the swelling pus-filled fluid was seen in the swelling. Although the animal was kept on medical treatment there was no improvement in condition. Hence scrotal ablation was performed under sedation using xylazine and local infiltration with lignocaine hydrochloride as a ring block anaesthesia. Post operatively the animal was kept on antibiotics for 5 days and non-steroidal anti-inflammatory for 3 days. The wound healing was normal without any complications.
\end{abstract}

Keywords: Gir bullock; Orchitis; Pyocoele; Scrotal ablation. 


\section{Introduction}

Orchitis is an inflammation of the testes which is characterized by presence of pain and warm swelling along with inflammatory changes. It may be primary or secondary and acute or chronic (Dalal et al., 2017). Pyocele is a condition involving collection of fluid surrounding the space of tunica vaginalis which is purulent in nature, it may be a consequence of orchitis or any bacterial infection. The occurrence of orchitis in bulls is not very often. The common causes of orchitis are trauma, application of any irritant toxins to scrotal region (O' Connor, 2005) and infection. The common infection causing organisms are Brucella abortus, Bovine Herpes Virus 1, Mycobacterium tuberculosis, Actinobacter pyogenes and Mycoplasma spp. Sometimes ascending infection from the urinary tract may also lead to orchitis. Faulty castration or improper technique of closed castration can sometimes lead to orchitis or pyocele (Kamalakar et al., 2014) Unilateral orchitis is more common than bilateral orchitis in bulls. As these conditions affect the normal work in working bulls and severely alter the reproductive performance of the bull, they require immediate attention. Scrotal ablation is the complete removal of the scrotum along with the affected testis. The surgical technique should be selected based upon the extent of involvement of the scrotum and the testis.

\section{Case History and Clinical Observation}

A Gir bullock, 4 years of age was presented to the Department of Veterinary Surgery and Radiology, Hebbal, Bengaluru with the complaint of swelling in the scrotal region since one month. Previously it was castrated two months back, hence orchitis was seen in only one testis due to faulty castration. Upon aspiration of the swelling pus-filled fluid was noticed from the swelling (Fig 1). Initially the pus-filled contents were drained from the swelling under local anaesthesia by giving a nick incision and animal was maintained on Inj Dicrysticin@5gm I/M and Inj Meloxicam @ $75 \mathrm{mg} \mathrm{I} / \mathrm{M}$ for one week in order to reduce the swelling and was advised to review after one week. As there was no improvement in condition even after one week of medical management it was decided to perform scrotal ablation.

\section{Treatment and Discussion}

The owner was advised to present the animal with 24 hours of complete fasting on the day of surgery. Hair around the scrotum and surrounding region was clipped. The scrotal region was scrubbed with surgical spirit and 5 per cent povidone iodine solution and area was prepared aseptically. Animal was sedated with xylazine @ $0.1 \mathrm{mg} / \mathrm{kg}$ bwt I/M (M/s Xylaxin, Indian Immunologicals, Hyderabad) and 2 per cent Lignocaine hydrochloride was infiltrated locally @ $30 \mathrm{ml}$ (LOX 2\%, Neon laboratories) as a ring block anaesthesia (Fig - 2). Circular skin incision was given at the neck of the scrotum extending upto the sub cutaneous tissue. The sub cutaneous tissue was bluntly dissected. The bleeding vessels were ligated using chromic catgut no 1 and chromic catgut no. 3. The spermatic cords were isolated after blunt dissection and were ligated by transfixation using chromic catgut no 3 and was severed distal to the ligature. Mass comprising of enlarged testis and scrotal skin was sharply excised and exteriorized. The sub cutaneous tissue was apposed using chromic catgut no. 3 in simple interrupted pattern followed by simple continuous pattern. Skin was sutured using trulon no. 2 in simple interrupted pattern (Fig - 3) The surgical site was cleaned and bandaging was done. Post operatively the animal was given antibiotic Inj Dicrysticin @ 5gm I/M for 5 days (Dicrysticin-S 2.5gm, Zydus AHL) and non-steroidal anti-inflammatory Inj Flunixin meglumine @ 1.1mg/kg I/M (Meglulast, Vet Mankind) along with regular wound dressing and suture removal on the $10^{\text {th }}$ post - operative day.

Closed method of castration using burdizzo's castrator is the simplest method of castration, it is important to avoid the testis and urethra during castration as it may lead to orchitis (Gupta and Khar, 2010) However this is not so commonly seen in bulls. It is important to maintain asepsis before and after burdizzo's method of castration to avoid complications like pyocele, scirrhous cord etc (Kamalakar et al., 2015) In orchitis, the ejaculates will contain leucocytes, there is reduced sperm motility and increased morphological abnormalities (Bell, 2006) If only one testis is affected then temperature dependent degenerative changes might be seen in the unaffected testis which will alter the normal production of the animal (Bell, 2006) In such cases unilateral orchidectomy can be performed. The case presented was a result of faulty castration method due to which orchitis developed in only one testis which affected the working of animal and there was no improvement in condition with medical management, hence scrotal ablation was performed. This technique of scrotal ablation is usually practiced in goats which showed signs of pyocele and orchitis and it is the only method for management of severe scrotal necrosis due to a faulty castration (Yadav et al., 2019) It is advisable to remove the remaining skin and underlying tissue in total ablation, in order to reduce the wound cavity and swelling which in turn reduces the healing time (Omar et al., 2013) Liberal removal of scrotal skin resulted in minimal post-operative complication after removal of large neoplastic testicle (Barber, 1985).

Orchitis in bulls can be avoided by providing immediate attention to any trauma to the scrotal region, by proper administration of antibiotics if it is due to an infection. The chances of orchitis due to faulty castration can be reduced when castration is performed by experienced persons and sterilized, proper instruments should be used. Castration should be performed in young animals and if any complications are noticed like pain, inflammation which should be managed 
by proper use of analgesics and anti - inflammatory. Improper castration in adult animals can lead to complications of orchitis, pyocoele or hydrocoele.

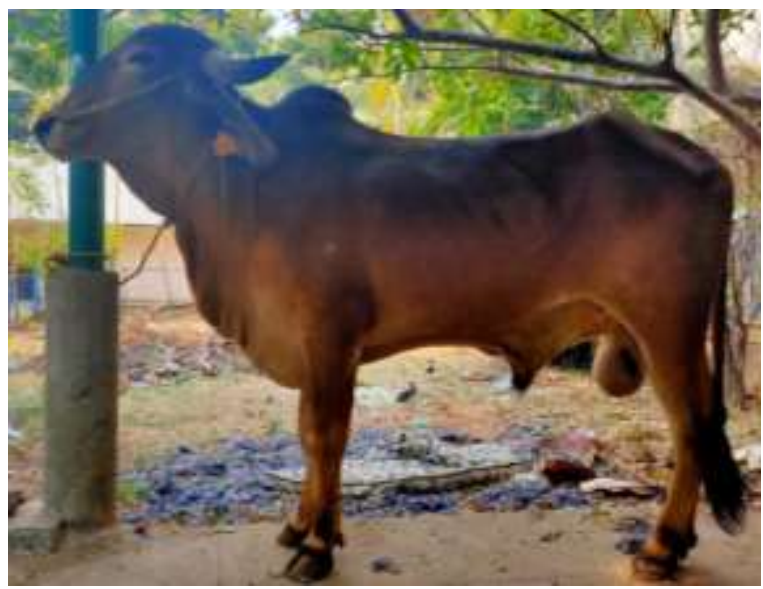

Fig 1: Photograph showing swelling in the scrotal region

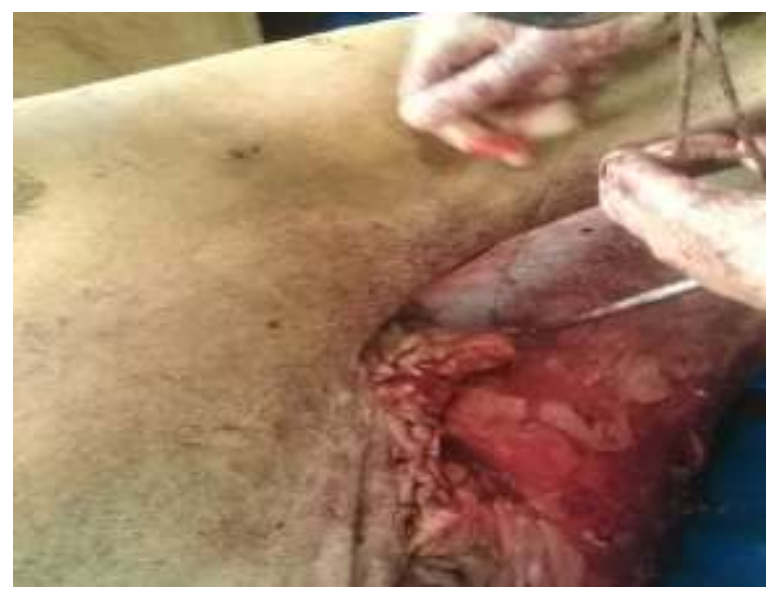

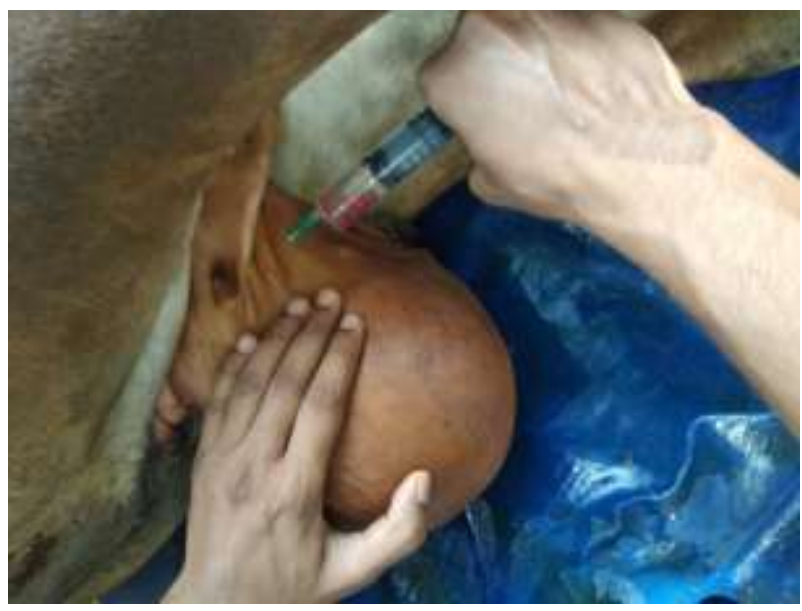

Fig 2: Photograph showing Local Infiltration of lignocaine hydrochloride as ring block anaesthesia

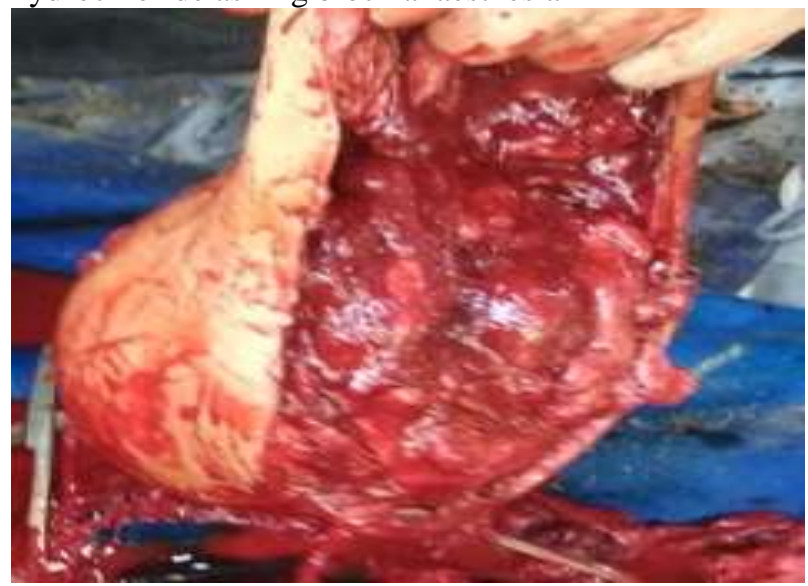

Fig $3 \& 4$. Photograph showing exteriorized scrotum with the affected testis and suturing of the skin

\section{References}

1) Barber, S.M., 1985. Castration of horses with primary closure and scrotal ablation. Veterinary Surgery., 14(1):2-6.

2) Bell, G., 2006. Diseases of the bovine scrotum. UK Vet Livestock .,11(7):19-23.

3) Dalal, J., Kumar, A. and Gupta, K., 2017. Management of unilateral chronic orchitis and hydrocele in a Sahiwal bull. Indian Veterinary Journal., 94(12):68-69

4) Gupta R.C. and Khar S.K., 2010. The Genital System. $9^{\text {th }}($ Ed), Ruminant Surgery. RPS Tyagi and Jit Singh C.B.S. Publishers, New Delhi : 274.

5) Kamalakar, G., Prasad, V.D., Mahesh, R. and Kumar, R.S., 2014. Surgical affections of Scrotum in bulls-A report of three cases. International Journal of Livestock Research., 4(7):67-71.

6) Kamalakar, G., Mahesh, R., Sumiran, N., Prasad, V.D., Devaratnam, J. and Kumar, R.S., 2015. Surgical management of Scirrhous Cord in Ongole bullocks-A report of two cases. Journal of Livestock Science., 6:97-99

7) O connor, J.J, (2005) Affections of male genital organs. 4th (Ed) Dollar's Veterinary surgery, C. B. S Publishers, New Delhi,740-746.

8) Omar, M.M.A., Hassanein, K.M.A., Abdel-Razek, A.R.K. and Hussein, H.A.Y., 2013. Unilateral orchidectomy in donkey (Equus asinus): Evaluation of different surgical techniques, histological and morphological changes on remaining testis. Veterinary Research Forum 4:(1) 1-6

9) Yadav, G.U., Lokhande, D.U., Dakhane, P.S. and Yamgar, A.T., 2019. Successful Surgical Management of Scrotal Necrosis in two Jamunapari Bucks. International Journal of Current Microbiology and Applied Sciences, 8(2):701-705. 